〈Research Paper〉

\title{
Anthraquinone-carbamodithiolate Assembly as Selective Chromogenic Chemosensor for $\mathrm{Fe}^{3+}$
}

\author{
Jin-Seok Bae, Seon-Yeong Gwon ${ }^{1}$ and Sung-Hoon Kim ${ }^{\dagger}$ \\ Department of Textile System Engineering, Kyungpook National University, Daegu, Korea \\ ${ }^{1}$ Department of Advanced Organic Materials Science and Engineering, Kyungpook National University, \\ Daegu, Korea
}

(Received: February 21, 2013 / Revised: March 4, 2013 / Accepted: March 5, 2013)

\begin{abstract}
A new assembly derived from 2,3-dibromo-5,6,7,8-tetrafluoroquinizarin and sodium diethyl-carbamodithiolate, was prepared as an efficient $\mathrm{Fe}^{3+}$ colorimetric chemosensor with high selectivity over other cations $\mathrm{Fe}^{3+}, \mathrm{Na}^{+}, \mathrm{Mg}^{2+}, \mathrm{Pb}^{2+}$, $\mathrm{Cd}^{2+}, \mathrm{Ni}^{2+}, \mathrm{Ca}^{2+}, \mathrm{Cu}^{2+}, \mathrm{Hg}^{2+}, \mathrm{Zn}^{2+}$ : from the dark blue to brown color change that is visible by eyes. This assembly produced large bathochromic shift of $228 \mathrm{~nm}$ in the presence of $\mathrm{Fe}^{3+}$ compared with the corresponding absorption maximum of the parent dye.
\end{abstract}

Keywords: anthraquinone, $\mathrm{Fe}^{3+}$ sensing, colorimetric, chemosensor, carbamodithiolate, intramolecular charge-transfer dye

\section{Introduction}

The sensing of metal cations using dye sensors has attracted much attention owing to its application in both chemical and environmental processes ${ }^{1-4)}$. There are already many chromogenic chemosensors developed for selective recognition of different species so far due to their high selectivity, sensitivity and simplicity ${ }^{5-7)}$. Iron is one of the most important elements amongst the transition and heavy metals for metabolic processes, being indispensable for plants and animals and therefore it is extensively distributed in environmental and biological materials ${ }^{8}$. If iron concentration of iron varies from the normal level it may become a potential health hazard e.g. it is well-known that an iron deficiency leads to anemia. Therefore, it is important to explore new chromogenic chemosensors for selective detection of iron. Over the past years, some examples for iron detection, including chromogenic ${ }^{9)}$ and fluorescent ${ }^{10-16)}$ chemical sensors, electrochemical devices $^{17)}$ have been reported. Currently, colorimetric sensors are popular due to their capability to detect analytes visually without resorting to any expensive

${ }^{\dagger}$ Corresponding author: Sung-Hoon Kim (shokim@knu.ac.kr) Tel.: +82-53-950-5641 Fax.: +82-53-950-6617

(c) 2013 KSDF 1229-0033/2013-03/13-17 instruments ${ }^{18)}$. Therefore, to develop a simple-to-use and visual diagnostic tool for the selective detection of iron is an interesting and timely research topic. Anthraquinone dyes are the second most important class after azo dyes. We have reported a number of different types of anthraquinone dyes for optical recording media ${ }^{19-21)}$. Herein, we report new colorimetric chemosensor based on an covalent assembly between an anthraquinone derivative and a carbamodithiolate, which have shown specifically specificity towards the $\mathrm{Fe}^{3+}$ ion

\section{Experimental}

Anthraquinone dye 4 was synthesized according to the literature method ${ }^{20,21)}$. All chemicals, including the perchlorate salts of various cations, namely $\mathrm{Fe}^{3+}, \mathrm{Na}^{+}$, $\mathrm{Mg}^{2+}, \mathrm{Pb}^{2+}, \mathrm{Cd}^{2+}, \mathrm{Ni}^{2+}, \mathrm{Ca}^{2+}, \mathrm{Cu}^{2+}, \mathrm{Hg}^{2+}, \mathrm{Zn}^{2+}$ and solvents were of the highest purity grade available and were used without further purification. UV-Vis spectra were measured using an Agilent 8453 spectrophotometer.

\section{Results and Discussion}

We designed and synthesized a highly selective chemosensor based on anthraquinone-carbamodithiolate assembly 
(ASSEM) for $\mathrm{Fe}^{3+}$ as shown in Scheme 1.

Tetrafluoroquinizarin 3 was synthesized by FriedelCrafts reaction of tetrafluorophthalic anhydride 1 with 1,4-dimethoxybenzene 2 in a $48 \%$ yield. Bromination of compound 3 was carried out in sulfuric acid with excess bromine. There action of compound 4 with sodium diethylcarbamodithiolate 5 gave 4-5 assembly ASSEM. Compound 4a subsequently tautomerized to tautomer $4 \mathrm{~b}$ under the reaction condition. Thus, tautomer $4 \mathrm{~b}$ was much more reactive than $4 \mathrm{a}$.

Tautomerism between $4 \mathrm{a}$ and $4 \mathrm{~b}$ in solution was not observed. Michael type nucleophilic substitution of the bromine atom by the carbamodithiolate anion gives the 9,10-anthraquinone derivative ASSEM.

We have quantitatively evaluated the color-structure relationship of anthraquinonoid dyes by means of the Pariser-Parr-Pople molecular orbital method (PPP $\mathrm{MO})^{22,23)}$. The first transition of anthraquinone dyes is caused by the intramolecular charge-transfer character ${ }^{22)}$, and the synthetic design of deep colored anthraquinone dyes is shown by Scheme 1, in which introduction of donor groups to 1-4 positions and/or that of acceptor groups such as fluorine atoms to 5-8 positions of anthraquinone may produce bathochromic shift of the first band. From these results, it was found that introduction of carbamodithiolate donor groups at 2and 3- position of anthraquinone nucleus may produce a bathochromic shift of the absorption maximum and studied the preparation of ASSEM. Figure 1 show the UV-Vis spectra of dye ASSEM (5 x $\left.10^{-5} \mathrm{molL}^{-1}\right)$ upon addition of 2 equivalents of carbamodithiolate 5 in $\mathrm{CH}_{3} \mathrm{CN}$ solution. Upon addition 5, we found new absorption bands appeared including the absorption at wavelength peak at $652 \mathrm{~nm}$ and $709 \mathrm{~nm}$. The color changed from brown to dark blue. ASSEM produces a bathochromic shift of $228 \mathrm{~nm}$ in comparison with the parent compound 4.

Here we report the cation sensing properties of a ASSEM containing dithionate groups. Owing to the well-defined assembly that contains an dithionate groups, it was anticipated that assembly could function as a host molecule for the recognition of cations via coordination.

This was investigated by adding various cations such<smiles>O=C1OC(=O)c2cc(F)ccc21</smiles>

1<smiles>COc1ccc(OC)cc1</smiles>

2

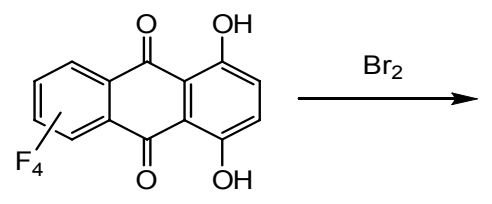

3

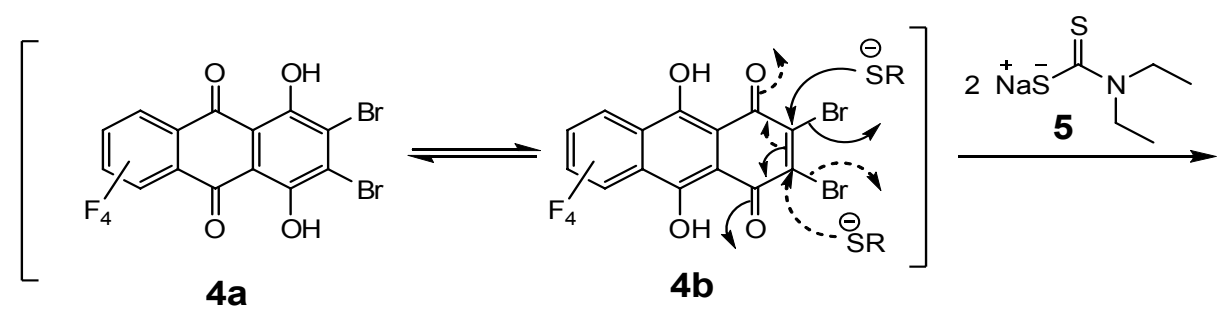

$4 a$

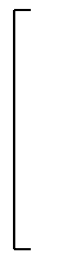

A

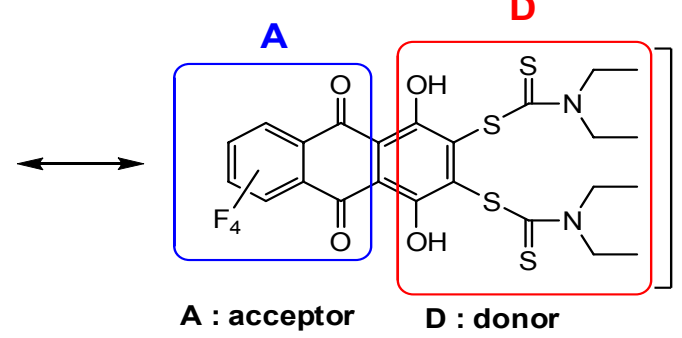

ASSEM

Scheme 1. Preparation and synthetic design of ASSEM 
as $\mathrm{Fe}^{3+}, \mathrm{Na}^{+}, \mathrm{Mg}^{2+}, \mathrm{Pb}^{2+}, \mathrm{Cd}^{2+}, \mathrm{Ni}^{2+}, \mathrm{Ca}^{2+}, \mathrm{Cu}^{2+}, \mathrm{Hg}^{2+}$, $\mathrm{Zn}^{2+}$, in their perchlorate salt, to a $5 \times 10^{-5} \mathrm{molL}^{-1}$ solution of ASSEM in acetonitrile and recording the changes in absorption spectra that occurred during the titration of the solution of ASSEM. Figure 2 shows, upon the addition of $\mathrm{Fe}^{3+}$ to the solution of ASSEM, the absorption band at 652 and $709 \mathrm{~nm}$ progressively decreased in intensity.

The mechanism for the decrease in absorbance was probably that the coordination to $\mathrm{Fe}^{3+}$ inactivated the sulfur atom in the electron transfer to the tetrafluoroanthraquinone moiety. In ASSEM, the sulfur atom having dithionate groups could be used as an electron donor with strong electron-donating ability.

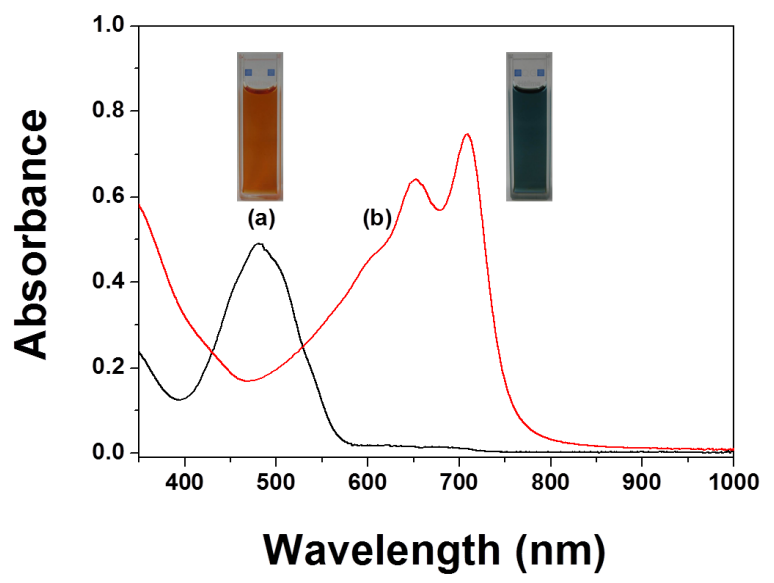

Figure 1. UV-Vis. spectra of $\mathrm{CH}_{3} \mathrm{CN}$ solution of (a) compound $4\left(5 \times 10^{-5} \mathrm{molL}^{-1}\right)$, (b) compound 4 in the presence of 2 equivalents of sodium carbamodithiolate 5 $\left(5 \times 10^{-5} \mathrm{molL}^{-1}\right)$.

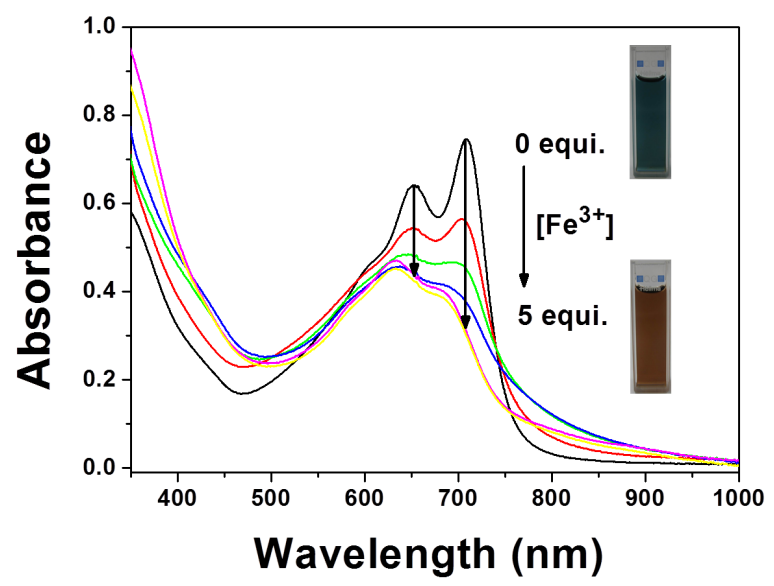

Figure 2. UV-Vis. spectra of $\operatorname{ASSEM}\left(5 \times 10^{-5} \mathrm{molL}^{-1}\right)$ upon addition of $\mathrm{Fe}^{3+}$ in $\mathrm{CH}_{3} \mathrm{CN}$ solution.

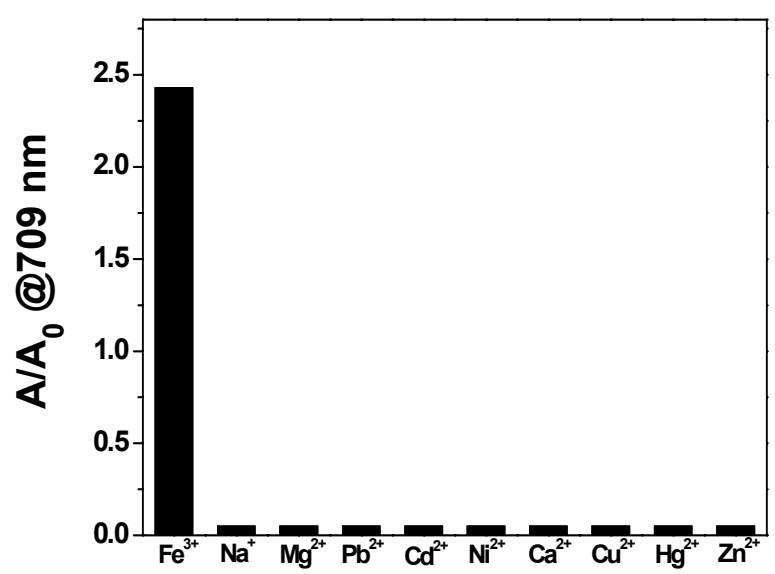

Figure 3. Comparison of absorption ratio for various cations.

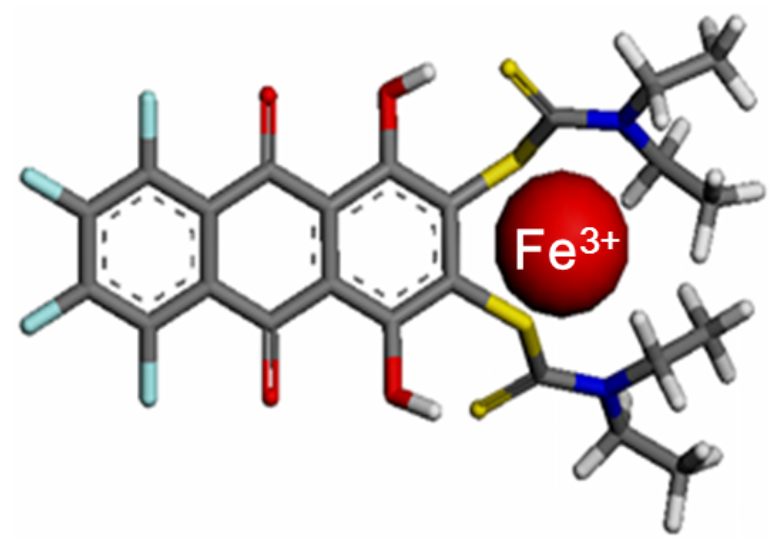

Figure 4. Optimized structure of ASSEM-Fe ${ }^{3+}$ complex.

Herein, the addition of $\mathrm{Fe}^{3+}$ might result in the binding of $\mathrm{Fe}^{3+}$ with dithionate $\mathrm{S}$, and then the $\mathrm{D}-\pi-\mathrm{A}$ structure transformed to A- $\pi-\mathrm{A}$ structure, which decreased the intramolecular charge-transfer from sulfur atom to the electron-accepting tetrafluoroanthraquinone moiety. However, none of the other anions investigated, namely as $\mathrm{Fe}^{3+}, \mathrm{Na}^{+}, \mathrm{Mg}^{2+}, \mathrm{Pb}^{2+}, \mathrm{Cd}^{2+}, \mathrm{Ni}^{2+}, \mathrm{Cu}^{2+}, \mathrm{Hg}^{2+}, \mathrm{Zn}^{2+}$ had any noticeable effect on absorption, as shown in Figure 3.

Theoretical calculations have been carried out to understand the nature of the binding between ASSEM and $\mathrm{Fe}^{3+}$ : $\mathrm{Fe}^{3+}$ cation is bridged between $\mathrm{N}$ atom together with dithiolate $\mathrm{S}$ in electron donor unit (Figure 4).

All theoretical calculations were performed by $\mathrm{DMol}^{3}$ program in the Materials Studio 4.2 package $^{23,24)}$ which is the quantum mechanical code using density functional theory. 


\section{Conclusion}

In conclusion, a new chromogenic chemosensor based on anthraquinone-carbamodithiolate assembly, ASSEM, was developed. It shows a good selectivity for $\mathrm{Fe}^{3+}$. ASSEM was not observed by absorption changes upon addition of other metal ions. The prepared ASSEM could be utilized as selective good chemosensor for $\mathrm{Fe}^{3+}$ in chemical, environmental and biological system.

\section{Acknowledgement}

This work was supported by Basic Science Research Program through the National Research Foundation (NRF) grant funded by the Korea Government (MEST) (No.2012-0000635). This research was supported by Kyungpook National University Research Fund, 2012.

\section{References}

1. S. Y. Kim and J. I. Hong, Chromogenic and Fluorescent Chemodosimeter for Detection of Fluoride in Aqueous Solution, Org. Lett., 9(16), 3109(2007).

2. A. Wiseman, "Handbook of Experimental Pharmacology XX/2 Part 2", Springer-Verlag, Berlin, pp. 48-97, 1990.

3. Y. Z. Lv, C. R. Li, L. Guo, F. C. Wang, Y. Xu, and X. F. Chu, Triethylamine Gas Sensor Based on $\mathrm{ZnO}$ Nanorods Prepared by a Simple Solution Route, Sensors and Actuators B: Chemical, 141 (1), 85(2009).

4. P. D. Beer and P. A. Gale, Anion Recognition and Sensing: The State of the Art and Future Perspectives, Angew. Chem. Int. Ed., 40(3), 486 (2001).

5. A. P. D. Silva, H. Q. N. Gunaratne, T. Gunnlaugsson, A. J. M. Huxley, C. P. McCoy, J. T. Rademacher, and T. E. Rice, Signaling Recognition Events with Fluorescent Sensors and Switches, Chem. Rev., 97(5), 1515(1997).

6. B. Valeur and I. Leray, Design Principles of Fluorescent Molecular Sensors for Cation Recognition, Coor. Chem. Rev., 205(1), 3(2000).

7. H. N. Kim, M. H. Lee, H. J. Kim, J. S. Kim, and J. Yoon, A New Trend in Rhodamine-based
Chemosensors: Application of Spirolactam Ringopening to Sensing Ions, Chem. Soc. Rev., 37(8), 1465(2008).

8. J. L. Bricks, A. Kovalchuk, C. Trieflinger, M. Nofz, M. Buschel, A. I. Tolmachev, J. Daub, and K. Rurack, On the Development of Sensor Molecules that Display Fe(III)-amplified Fluorescence, J. Am. Chem. Soc., 127(39), 13522(2005).

9. Z. Q. Liang, C. X. Wang, J. X. Yang, H. W. Gao, Y. P. Tian, X. T. Tao, and M. H. Jiang, A Highly Selective Colorimetric Chemosensor for Detecting the Respective Amounts of Iron(II) and Iron(III) Ions in Water, New. J. Chem., 31(6), 906(2007).

10. M. Zhang, Y. H. Gao, M. Li, M. Yu, F. Li, L. Li, M. Zhu, J. Zhang, T. Yi, and C. H. Huang, A Selective Turn-on Fluorescent Sensor for Fe(III) and Application to Bioimaging, Tetra. Lett., 48(21), 3709(2007).

11. X. B. Zhang, G. Cheng, W. J. Zhang, G. L. Shen, and R. Q. Yu, A Fluorescent Chemical Sensor for $\mathrm{Fe}^{3+}$ Based on Blocking of Intramolecular Proton Transfer of a Quinazolinone Derivative, Talanta, 71(1), 171(2007).

12. O. Oter, K. Ertekin, R. Kilincarslan, M. Ulusoy, and B. Cetinkaya, Photocharacterization of a Novel Fluorescent Schiff Base and Investigation of its Utility as an Optical $\mathrm{Fe}^{3+}$ Sensorin PVC Matrix, Dyes. and Pigm., 74, 730(2007).

13. Y. Ma, W. Luo, P. J. Quinn, Z. Liu, and R. C. Hider, Design, Synthesis, Physicochemical Properties, and Evaluation of Novel Iron Chelators with Fluorescent Sensors, J. Med. Chem., 47(25), 6349 (2004).

14. Y. Xiang and A. Tong, A New Rhodamine-based Chemosensor Exhibiting Selective Fe(III)-amplified Fluorescence, Org. Lett., 8(8), 1549(2006).

15. Y. Son and J. Park, Rhodamine 6G Based New Fluorophore Chemosensor Toward $\mathrm{Hg}^{2+}$, Textile Coloration and Finishing(J. Korean Soc. Dye. and Finish.), 24(3), 158(2012).

16. H. Kim and Y. Son, Synthesis and Optical Properties of Novel Chemosensor Based on Rhodamine 
6G, Textile Coloration and Finishing(J. Korean Soc. Dye. and Finish.), 24(4), 233(2012).

17. R. D. Marco and J. Martizano, Response of a Copper(II) and Iron(III) Ion-selective Electrode Bielectrode Array in Saline Media, Talanta, 75(5), 1234(2008)

18. Y. F. Cheng, M. Zhang, H. Yang, F. Y. Li, T. Yi, and C. H. Huang, Azo Dyes Based on 8hydroxyquinoline Benzoates: Synthesis and Application as Colorimetric $\mathrm{Hg}^{2+}$-Selective Chemosensors, Dyes. and Pigm., 76(3), 775(2008).

19. M. Matsuoka, S. H. Kim, and T. Kitao, Novel Syntheses of Quinone-type i.r. Dyes for Optical Recording Media, J. Chem. Soc. Chem. Commun., 17, 1195(1985)

20. S. H. Kim, M. Matsuoka, and T. Kitao, Novel
Syntheses of phenoselenazinequinone Infrared Dyes, Chem. Lett., 14, 1351(1985).

21. S. H. Kim, M. Matsuoka, Y. Kubo, T. Yodoshi, and T. Kitao, Novel Syntheses of Anthraquinonoid Near-infrared Absorbing Dyes, Dyes. and Pigm., 7(2), 93(1986).

22. Y. Kogo, H. Kikuchi, M. Matsuoka, and T. Kitao, Colour and Constitution of Anthraquinonoid Dyes, Part 1-Modified PPP Calculations and Substituent Effects, J. Soc. Dyers. Colour., 96(9), 475(1980).

23. B. Delley, An All-electron Numerical Method for Solving the Local Density Functional for Polyatomic Molecules, J. Chem. Phys., 92(1), 508(1990).

24. B. Delley, From Molecules to Solids with the DMol $^{3}$ Approach, J. Chem. Phys., 113(17), 7756 (2000) 